\title{
Role of hysterolaparoscopy in unexplained infertility
}

\author{
Shubha Choudhary ${ }^{1}$, Meena Priyadharshini V. ${ }^{2 *}$, Ameya Sirsat ${ }^{3}$, Sunita R. Tandulwadkar
}

\author{
${ }^{1}$ Department of Obstetrics and Gynecology, Deen Dayal Upadhyay Hospital, New Delhi, India \\ ${ }^{2}$ Department of Obstetrics and Gynecology, PSG Institute of Medical Sciences and Research, Tamil Nadu, India \\ ${ }^{3}$ Consulting Fertility Specialist \& Laparoscopic Surgeon, Rotunda CHR \& Dr Tilak Hospital, Mumbai, Maharashtra, \\ India \\ ${ }^{4}$ Department of Obstetrics and Gynecology, Ruby Hall, Pune, Maharashtra, India
}

Received: 02 June 2019

Accepted: 17 June 2019

\section{*Correspondence:}

Dr. Meena Priyadharshini,

E-mail: drmeenushiv@gmail.com

Copyright: ( ) the author(s), publisher and licensee Medip Academy. This is an open-access article distributed under the terms of the Creative Commons Attribution Non-Commercial License, which permits unrestricted non-commercial use, distribution, and reproduction in any medium, provided the original work is properly cited.

\begin{abstract}
Background: Infertility, as defined by World Health Organization (WHO), is failure to achieve pregnancy during 1 year of regular unprotected intercourse. The objective of this study was to determine the incidence of unsuspected pathology at hysterolaparoscopy in presumed unexplained infertility, the incidence of intervention done for correcting pathology and its outcome and the importance of hysterolaparoscopy in the evaluation and treatment of infertile couples.

Methods: This prospective observational study was carried out at IVF and Endoscopy centre, Department of obstetrics and gynecology at the Ruby Hall clinic, Pune from $1^{\text {st }}$ November 2014 to $30^{\text {th }}$ July 2016, after obtaining institutional ethical clearance and who met the inclusion and exclusion criteria. A detailed clinical history and physical examination and bimanual pelvic examination were done, following which all the patients were subjected to baseline blood investigation, 3D pelvis (TVS) and semen analysis. Day care hysterolaparoscopy was performed and systematic analysis were done.

Results: The mean duration of infertility was 2 to 4 years. In our study out of 75 women $62(82.67 \%)$ showed normal hysteroscopic findings, remaining 13 women (17.67\%) showed abnormal hysteroscopic findings like cornaul blockage, intrauterine adhesions and tuberculosis endometrium. Abnormal laparoscopic findings were reported in $29.33 \%$ of which the most common pathology was endomertiosis $(21.33 \%)$.

Conclusions: Diagnostic Hysterolaproscopy is a safe, effective, minimally invasive, cost effective, daycare comprehensive procedure in evaluation of unexplained infertility. Apart from routine diagnostic protocol missed pathologies can be detected and this tool can be used for diagnostic as well as therapeutic intervention.
\end{abstract}

Keywords: 3D ultrasound pelvis, Cornual blockage, Endometriosis, Hysterolaproscopy, Intrauterine adhesions, Unexplained infertility

\section{INTRODUCTION}

Infertility, as defined by World Health Organization (WHO), is failure to achieve pregnancy during 1 year of regular unprotected intercourse. Globally $10 \%$ to $15 \%$ of couples experience difficulty in conceiving a child. ${ }^{1,2}$ Conception depends upon the fertility potential of both male and female partner. ${ }^{3}$ Male is directly responsible in about $30-40 \%$ while female in about $30-40 \%$ and both are responsible in about $10 \%$ of cases. Remaining $10 \%$ cases are unexplained. Unexplained infertility refers to the absence of a definable cause for a couple's failure to achieve pregnancy after 12 months of attempting conception despite a thorough evaluation, or after six months in women 35 and older. The diagnosis of unexplained infertility can be made only after excluding 
common causes of infertility using standard fertility investigations, which include semen analysis, assessment of ovulation, and tubal patency test. These tests have been selected as they have definitive correlation with pregnancy. ${ }^{4}$ It is estimated that a standard fertility evaluation will fail to identify an abnormality in approximately $15 \%$ to $30 \%$ of infertile couples. ${ }^{4}$ Combined hysterolaparoscopy make it possible to evaluate completely and treat in the same sitting. Although pelvic sonography and HSG are good enough to exclude gross intrauterine pathology, subtle changes need be found and treated with hysteroscopy.

Hysteroscopy and laparoscopy are the two methods for evaluation and treatment of tubal pathology and are complementary to each other. Given that it allows direct visual examination of the pelvic reproductive anatomy, it is the test of choice to identify otherwise unrecognized peritoneal factors that influence fertility, specifically endometriosis and pelvic adhesions. ${ }^{5,6} \mathrm{We}$ are aware that, even though there is tremendous advancement in radio imaging sciences with 3D/4D technologies, uterine polyps, few adhesion bands, pelvic/peritoneal/ periovarian adhesions, pelvic endometriosis can still be missed which can lead to subfertility. Hence, this study was undertaken to evaluate the role of hysterolaparoscopy in unexplained infertility.

Objectives of the current study include a) determining the incidence of unsuspected pathology at hysterolaparoscopy in presumed unexplained infertility, b) to determine the incidence of intervention done for correcting pathology and its outcome, and c) to determine the importance of hysterolaparoscopy in the evaluation and treatment of infertile couples.

\section{METHODS}

This prospective observational study was carried out at IVF and Endoscopy centre, Department of Obstetrics and Gynecology at the Ruby Hall clinic, Pune from $1^{\text {st }}$ November 2014 to $30^{\text {th }}$ July 2016, after obtaining institutional ethical clearance and who met the inclusion and exclusion criteria. The total number of study participants were 75 of age group 21 to 35 years of age with primary infertility.

A detailed clinical history and physical examination and bimanual pelvic examination were done, following which all the patients were subjected to baseline blood investigation, 3D pelvis (TVS) and semen analysis.

\section{Inclusion criteria}

- Women in age group 21 to 35 year

- Failure to conceive after 1 year of unprotected intercourse

- Primary infertility

- Regular cycles
- Good ovarian reserve (as assessed by Antral follicle count on day $2 / 3$ or $\mathrm{AMH}$ )

- Normal hormonal profile (ex-S. Prolactin and Thyroid profile)

- Normal semen analysis

- No ultrasonography showing normal uterus, normal ovaries, no probe tenderness, no s/o any pelvic pathology.

\section{Exclusion criteria}

- $\quad$ Age $<21$ years or $>35$ years

- Associated male factor infertility

- Poor ovarian reserve (as assessed by Antral follicle count on day $2 / 3$ or $\mathrm{AMH}$ )

- Secondary infertility

- Any known cause of infertility (like tubal/ ovarian/ pelvic factors)

Hysterolaparoscopy was done as a day- care procedure under general anaesthesia. It was performed in the postmenstrual phase of the cycle (day 4 to 8), after basic preoperative evaluation of the patient. With written informed consent, hysteroscope was introduced intracervically, with distension media as normal saline and Panaromic view of the uterine cavity and bilateral ostia visualised. According to the findings, either diagnostic or operative hysteroscopy was done. Normal hysteroscopy was labelled where no pathology was seen and bilateral ostia were healthy looking. Abnormal hysteroscopy was labelled where ever polyps or hyperplasia of endometrium, septum, synechiae (intrauterine adhesion), and fibrosed ostia were observed. Therapeutic interventions were undertaken if any pathology was seen using operative hysteroscope/ resectoscope. Interventions done were in the form of synechiolysis (adhesiolysis), polypectomy, and cannulation. Three- puncture laparoscopy was then performed. Primary port was created infra umbilically with a $10 \mathrm{~mm}$ trocar after creating pneumoperitoneum with $\mathrm{CO}_{2}$ using Veress needle. $5 \mathrm{~mm}$ ipsilateral ancillary ports were placed for instrumentation. Depending on the pathology found, either diagnostic or operative laparoscopy was performed. Chromopertubation was done with methylene blue. Normal laparoscopy was labelled in the absence of any pathology. Abnormal laparoscopic findings were labelled in the presence of tubal occlusion (unilateral or bilateral), adhesions peritubal, peritoneal, perihepatic, endometriosis, small fibroid seedlings, paratubal or fimbrial cysts etc. If endometriosis was found it was graded as per revised ASRM grading. Therapeutic intervention was done at the same sitting in the form of adhesiolysis, fimbrioplasty, and ablation of endometriotic spots and cystectomy. Thorough pelvic lavage was performed at the end of the procedure in all cases, thus resulting in a clean pelvic cavity. Finally laparoscopic survey was done to inspect other abdominal viscera. 


\section{RESULTS}

In our study of 75 patients with unexplained infertility who underwent laparo-hysteroscopic evaluation, 25 out of 75 patients (33.3\%) had a history of infertility since 2-4 years. The distribution of patients as per duration of infertility was even, as there were similar number of women with duration of infertility <2 years $(15 / 75$ women - 20\%), 4-6 years (20/75 women - 26.7\%) and $>6$ years $(15 / 75$ women $-20 \%)$.

In our study of 75 women, 62 women (82.67\%) showed normal hysteroscopic findings. Remaining 13 women $(17.67 \%)$ showed abnormalities on hysteroscopy. Of the 13 women who had abnormal hysteroscopy, 5 belonged to 21-25 years age group, 5 belonged to 26-30 years age group and 3 were in the age group of 31-35 years.

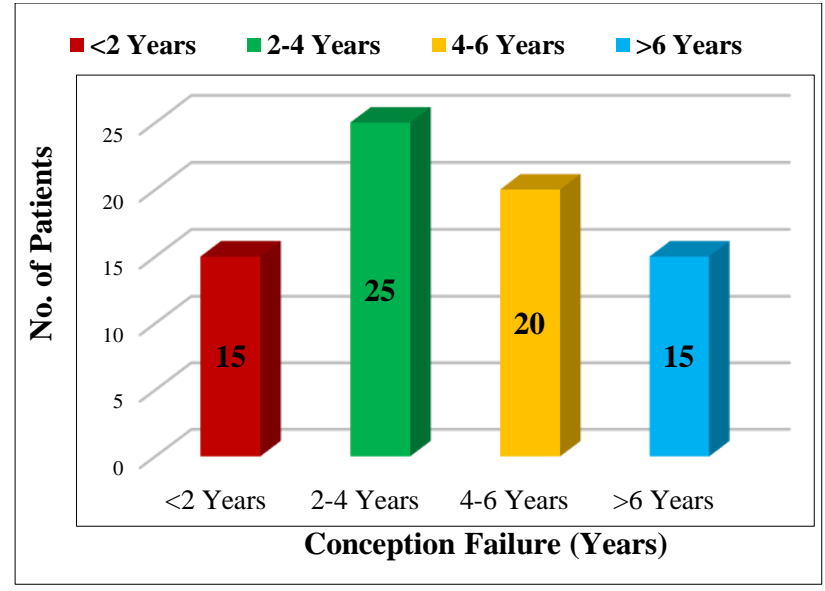

Figure 1: Distribution of patients as per duration of infertility.

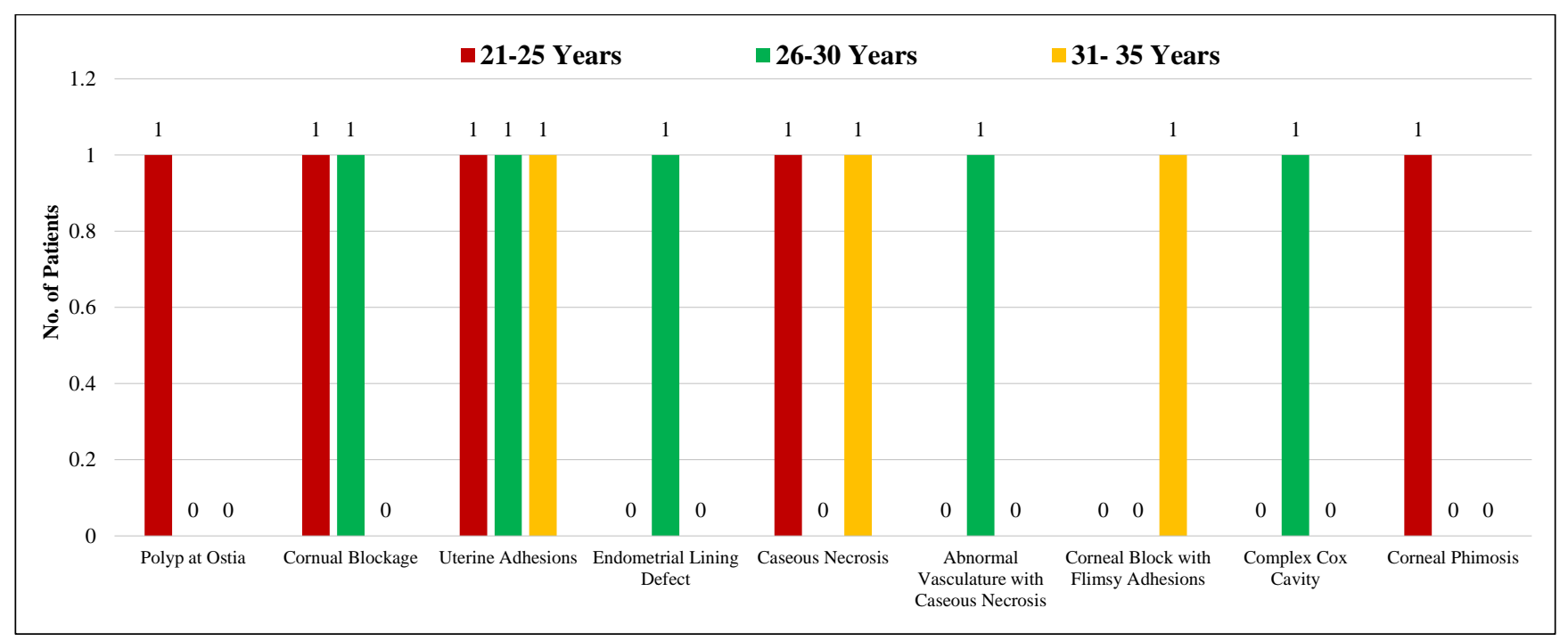

Figure 2: Age wise distribution of hysteroscopic findings.

Table 1: Incidence of pathologies on hysteroscopy.

\begin{tabular}{|llllll|}
\hline Pathology & $\begin{array}{l}21-25 \\
\text { years }\end{array}$ & $\begin{array}{l}26-30 \\
\text { years }\end{array}$ & $\begin{array}{l}31-35 \\
\text { years }\end{array}$ & $\begin{array}{l}\text { Incidence } \\
(\text { No. })\end{array}$ & $\begin{array}{l}\text { Incidence } \\
(\%)\end{array}$ \\
\hline Polyp at Ostia & 1 & 0 & 0 & 1 & 1.33 \\
\hline Cornual Blockage & 1 & 1 & 0 & 2 & 2.67 \\
\hline Intrauterine Adhesions & 1 & 1 & 1 & 3 & 2.67 \\
\hline Abnormal endometrium & 0 & 1 & 0 & 1 & 1.33 \\
\hline Kochs (Confirmed on DNA-PCR) & 1 & 0 & 1 & 2 & 2.67 \\
\hline Abnormal Vasculature with Caseous Necrosis & 0 & 1 & 0 & 1 & 1.33 \\
\hline Corneal Block with Flimsy Adhesions & 0 & 0 & 1 & 1 & 1.33 \\
\hline Complex Koch's Cavity & 0 & 1 & 0 & 1 & 1.33 \\
\hline Cornual Phimosis & 1 & 0 & 0 & 1 & 1.33 \\
\hline Total & $\mathbf{5}$ & $\mathbf{5}$ & $\mathbf{3}$ & $\mathbf{1 3 / 7 5}$ & $\mathbf{1 7 . 3 3}$ \\
\hline
\end{tabular}




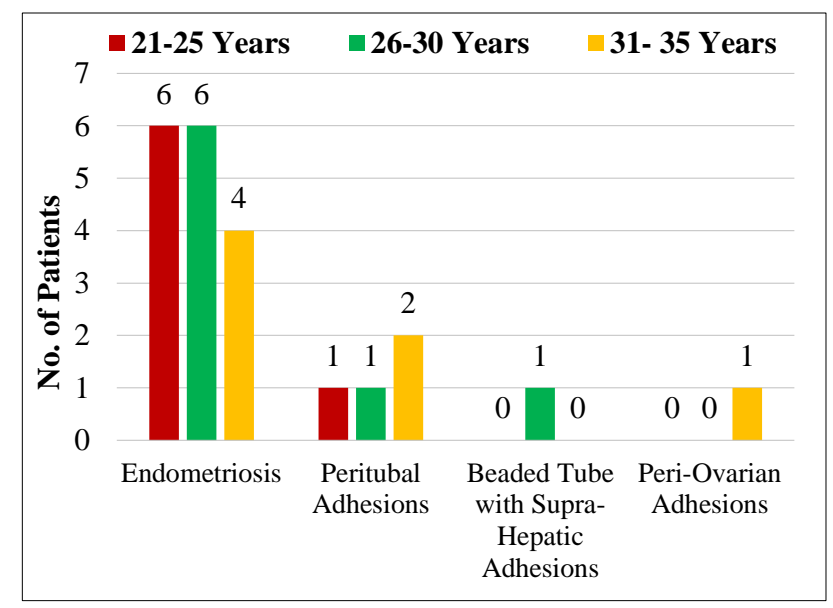

Figure 3: Age wise distribution of laproscopic findings.
In our study of 75 women, 53 women $(70.67 \%)$ showed normal hysteroscopic findings. Remaining 22 women $(29.33 \%)$ showed abnormalities on hysteroscopy. The 22 women, who showed abnormalities on laparoscopy, were almost equally divided amongst the 3 age groups $-7,8$ and 7 in 21-25 years, 26-30 years and 31-35 years respectively.

In our study of 75 patients, the 3 most common pathologies were cornual blockage (2.67\%), intra-uterine adhesions $(2.67 \%)$ and tuberculosis on DNA-PCR (2.67\%).

The other abnormalities detected on hysteroscopy were polyp at ostia, abnormal endometrium, abnormal vasculature with caseous necrosis, corneal block with flimsy adhesions, complex Koch's cavity and cornual phimosis.

Table 2: Incidence of pathologies on laproscopy.

\begin{tabular}{|c|c|c|c|c|c|}
\hline Pathology & $\begin{array}{l}21-25 \\
\text { years }\end{array}$ & $\begin{array}{l}26-30 \\
\text { years }\end{array}$ & $\begin{array}{l}31-35 \\
\text { years }\end{array}$ & $\begin{array}{l}\text { Number } \\
\text { of women }\end{array}$ & $\%$ \\
\hline Endometrosis & 6 & 6 & 4 & 16 & 21.33 \\
\hline Peritubal/Perifimbrial adhesions & 1 & 1 & 2 & 4 & 5.33 \\
\hline Beaded tube with pelvic and suprahepatic adhesions & 0 & 1 & 0 & 1 & 1.33 \\
\hline Peri-ovarian adhesions & 0 & 0 & 1 & 1 & 1.33 \\
\hline Total & 7 & 8 & 7 & $22 / 75$ & 29.33 \\
\hline
\end{tabular}

Table 3: Hysterolaproscopic intervention in the same sitting

\begin{tabular}{|c|c|c|c|c|c|}
\hline Procedure & $\begin{array}{l}\text { Hystero- } \\
\text { performed }\end{array}$ & $\begin{array}{l}\text { edures } \\
\lg \end{array}$ & \multicolumn{3}{|c|}{ Laproscopic procedures performed in same sitting } \\
\hline Intervention & $N=(5 / 75)$ & $\%$ & Procedure & $N=(22 / 75)$ & $\%$ \\
\hline Uterine adhesinolysis & 2 & 2.67 & $\begin{array}{l}\text { Bipolar endocoagulation } \\
\text { of endometriotic spots }\end{array}$ & 16 & 21.33 \\
\hline Polypectomy & 1 & 1.33 & \multirow{2}{*}{ Pelvic Adhesinolysis } & \multirow{2}{*}{6} & \multirow{2}{*}{8} \\
\hline Cornual recanulation & 2 & 2.67 & & & \\
\hline
\end{tabular}

The commonest pathology found in our study was endometriosis. It was seen in $16 / 75$ women who underwent laparo-hysteroscopy for unexplained infertility $(21.33 \%)$. The other pathologies found on laparoscopy were peri-tubal adhesions, beaded tube with pelvic adhesions and peri-ovarian adhesions.

Of the 75 women who underwent hysero-laparoscopy for unexplained infertility, 5 underwent therapeutic procedure in the same sitting. 2 women underwent uterine adhesiolysis for uterine synechae, 1 underwent hysteroscopic polypectomy, and 2 underwent cornual recanulation for blocked fallopian tubal cornua.

\section{DISCUSSION}

Hystereolaparoscopy has been proven as an effective tool in investigation of unexplained infertility patients for therapeutic interventions or early decisions for artificial reproductive technique. ${ }^{7}$ Duration of infertility is an important factor when laparo-hysteroscopy is being studied for unexplained infertility. In our study, Figure 1 25 out of 75 patients $(33.3 \%$ ) had a history of infertility with mean duration of 2-4 years. A similar study by Ashraf et al, shows maximum number of patients presented after 2-5 year of failure to conceive. ${ }^{8}$ Jayakrishnan $\mathrm{K}$ et al. found a slightly higher mean duration of infertility in their study. ${ }^{9}$ 
In our study of 75 women, 62 women $(82.67 \%)$ showed normal hysteroscopic findings. Remaining 13 women $(17.67 \%)$ showed abnormalities on hysteroscopy. This rate of abnormal hysteroscopic finding is comparable to those obtained by Singh R et al, (14.67\%), Parveen S et al, $(19.33 \%)$, Boudhara K et al, $(16.63 \%)$ and Malhotra et al, $(18 \%) .{ }^{10-13}$ On hysteroscopy in our study the three most common pathologies were, cornual blockage (2.67\%), Singh et al, and Parveen et al, observed corneal block in $2.67 \%$ and $1.33 \%$ respectively intra-uterine adhesions (2.67\%) and Parveen et al, observed tuberculosis endometrium in $1 \%$ of study group endometrial tuberculosis on DNA-PCR (2.67\%). ${ }^{10,11}$ Ashraf et al, in his study observed 3\% of intrauterine adhesions. ${ }^{8}$ Abnormal vasculature with caseous necrosis, flimsy adhesions at cornual block observed in our study have not been reported in most of the studies.

On laparoscopy, our study reported abnormalities in $29.33 \%$ of women. These figures are comparable to those by Boudhara et al, (26\%), Parveen S et al, (26\%), Singh $\mathrm{R}$ et al, (33\%), Malhotara $\mathrm{N}$ et al, (24\%). The commonest pathology found on laparoscopy in our study was endometriosis 16/75 (21.33\%). Ashraf et al, and Bhandhari S et al, observed endometriosis in $18.8 \%$ and $45 \% .8,14$ The other pathologies found on laparoscopy were peri-tubal adhesions $(5.33 \%)$, beaded tube with pelvic adhesions $(1.33 \%)$ and peri-ovarian adhesions $(1.33 \%)$. Tsuji I et al, And Bonneau $\mathrm{C}$ et al, observed in $8.8 \%$ of patients observed peritubal adhesions in $5.3 \%$ of patients. $^{15,16}$

One of the strengths of the study was that it can analyse the women who could undergo therapeutic procedures in the same setting. Interventions which were performed hysteroscopically in same sitting were intrauterine adhesiolysis (2.67\%), hysteroscopic polypectomy $(1.33 \%)$ and cornual cannulation (2.67\%). These findings were similar to Singh R et al. In our study, laparoscopic intervention was performed in the same sitting by doing adhesiolysis in $8 \%$ cases and bipolar endocoagulation in $21.33 \%$. The study by Boudhara $\mathrm{K}$ et al, reported results of adhesiolysis performed in $8 \%$ and bipolar endocoagulation in $18 \%$.

Limitations of this study involve that in spite of extensive evaluation of unexplained infertility with various modalities of testing including a diagnostic hysterolaparoscopy, few causes of infertility continue to remain unexplained. Quality of oocytes, abnormalities in fertilisation like zona pellucida thickness, poor cumulus, and sperm penetration abnormalities cannot be assessed by hysterolaparoscopy.

\section{CONCLUSION}

Diagnostic hysterolaproscopy is a safe, effective, minimally invasive, cost effective, day care comprehensive procedure in evaluation of unexplained infertility. Apart from routine diagnostic protocol, missed pathologies can be detected and this tool can be used for diagnostic as well as therapeutic intervention.

Funding: No funding sources

Conflict of interest: None declared

Ethical approval: The study was approved by the Institutional Ethics Committee

\section{REFERENCES}

1. Dyer SJ. International on infertility prevalence and treatment seeking: Potential need and demand for medical care. Hum Reprod. 2009;24:2379-80.

2. The Practice Committee of the American Society for Reproductive Medicine. Optimal evalution of the infertile female. Fertil Steril. 2006;86(5 suppl):S264S267.

3. Esmaeilzadeh S, Delavar MA, Zeinalzadeh M, Mir MR. Epidemiology of infertility: a population-based study in Babol, Iran. Women Health. 2012;52:744.

4. Boivin J, Bunting L, Collins JA, Nygren KG. International estimates of infertility prevalence and treatment seeking. Potential need and demand for infertility and medical care. Humreprod. 2007;22:1506-12.

5. Rajan R. Postgraduate obstetrics, gynaecology, infertility and clinical endocrinology. 1st Ed. New Delhi: Jaypee Brothers; Chapter I, Practical management of infertility: An approach based on 1, pregnancies recorded over 12 years of experiences; 2005:3-17.

6. Gelbaya TA, Potdar N, Jeve YB, Nardo LG. Definition and Epidemiology of Unexplained Infertility. Obstet Gynecol Surv. 2014;69(2):109-15.

7. Begum J, Samal S, Ghose S, Palai P, Samal R. Combined hysterolaparoscopy as an early option for initial evaluation of female infertility: A retrospective study of 135 patients. Int $\mathbf{J}$ Reprod Contracept Obstet Gynecol. 2015;4:584-8.

8. Ashraf M Kansoth AM, Elbalshy AE. Laparoscopic presentation in unexplained infertility; a retrospective study. J Med Sci Res. 2018;1:312-6.

9. Jaykrishnan, Koshy AK, Raju R. Role of laparohysteroscopy in women with normal pelvic imaging and failed ovulation stimulation with intrauterine insemination. J Hum Reprod Sci. 2010;3:20-4.

10. Chanu SM, Rudra Pal GS, Panda S, Santa Singh AS. Diagnostic hysterolaparoscopy for evaluation of infertility: Our experience in a tertiary Care Hospital. J Hum Reprod Sci. 2018;11:19-23.

11. Parveen S, Khanna M. Role of combined diagnostic laproscopy and simultaneous diagnostic hysteroscopy for evaluation of female subfertility factors. J SurgPak (Int). 2010;15(1):44-7.

12. Boudhraa K, Jellouli MA, Kassasoui O, Ben Aissia $\mathrm{N}$, Ouerhani R, Triki A, et al. Role of the hysteroscopy and laproscopy in management of the female infertility: about 200 cases. Tunis Med. 2009;87(1):55-60. 
13. Malhotra N, Sood M. Role of hysteroscopy in infertile women. Department of Obstetrics and Gynaecology, Lady Hardinge Medical College, New Delhi.J India Med Assoc. 2001;95(9):499-525.

14. Bhandhari S, Singh A, Agarwal P, Ganguli I. Findings in diagnostic laparoscopy in patients with unexplained infertility. Fertil Sci Res. 2015;2:29-33.

15. Tsuji I, Ami K, Miyazakai A, Hujinami N, Hoshiai $\mathrm{H}$, Benefit of diagnostic laparoscopy for patients with unexplained infertility and normalhysterosalpingography findings. Tohoku J Exp Med. 2009;219:39-42.
16. Bonneau C, Chanelles O, Sifer C, Poncelet C. Use of laparoscopy in unexplained infertility. Eur J Obstet Gynecol Reprod Biol. 2012;163:57-61.

Cite this article as: Choudhary $S$, Priyadharshini MV, Ameya S, Tandulwadkar SR. Role of hysterolaparoscopy in unexplained infertility. Int J Reprod Contracept Obstet Gynecol 2019;8:2592-7. 